\title{
ATIVIDADE ANTIMICROBIANA E DESINFECÇÃO HOSPITALAR COM EXTRATO DE CRAVO-DA-ÍNDIA \\ (SYZYGIUM AROMATICUN E/OU CARYOPHYLLUS AROMATICUS L.)
}

Antimicrobial activity and hospital disinfection with clove extract (Syzygium aromaticun and/or Caryophyllus aromaticus L.)

\author{
HORVAT, Elizabeta ${ }^{1}$; MIYASAKA, Natália Reiko Sato ${ }^{2}$; \\ ${ }^{1}$ Graduando do Curso de Biomedicina - Universidade São Francisco; ${ }^{2}$ Professora do Curso de \\ Biomedcina - Universidade São Francisco) \\ horvatelizabeta@gmail.com
}

\begin{abstract}
RESUMO. A resistência a drogas de patógenos humanos tornou-se um problema de saúde pública devido à redução na eficácia terapêutica a diversos antimicrobianos e a procura de substâncias que apresentem atividade antimicrobiana é grande, principalmente em relação a cepas provenientes de ambiente hospitalar, assim, torna-se importante a busca constante de novas substâncias capazes de inibir microrganismos patógenos a partir de fontes naturais. Este trabalho teve por objetivo avaliar qualitativamente a atividade antimicrobiana in vitro do extrato alcoólico de botões florais secos de cravo-da-índia (Syzygium aromaticum e/ou Caryophyllus aromaticus L.) frente às linhagens bacterianas Gram-negativas Salmonella sp, Klebsiella pneumoniae Carbapenemase, Pseudomonas aeruginosa, frente às bactérias Grampositivas Streptococcus mutans, Streptococcus pyogenes, Streptococcus agalactiae, Staphylococcus aureus e o fungo Candida albicans. A avaliação antimicrobiana dos extratos foi realizada pelo método de disco-difusão e indicaram que todas as cepas utilizadas neste estudo foram sensíveis aos extratos testados. Com o aumento na incidência de doenças infecciosas provocadas por resistência bacteriana devido ao uso irracional de antimicrobianos deu-se o surgimento de cepas multirresistentes, principalmente relacionados a pacientes hospitalizados e imunocomprometidos, tornando-se assim de grande interesse científico nas últimas décadas a procura e obtenção de substâncias que apresentem atividade antimicrobiana e que inibam o crescimento de microrganismos patogênicos.
\end{abstract}

Palavras-chave: Atividade antimicrobiana, Syzygium aromaticum e/ou Caryophyllus aromaticus L., Desinfecção hospitalar, Cravo-da-índia.

ABSTRACT. The resistance to drugs of human pathogens has become a public health problem due to the reduction in therapeutic efficacy to several antimicrobials and the demand for substances that present antimicrobial activity is great, mainly in relation to strains coming from hospital environment, the constant search for new substances capable of inhibiting pathogenic microorganisms from natural sources is important. This work aimed to qualitatively evaluate the in vitro antimicrobial activity of the alcoholic extract of dried floral buds of clove (Syzygium aromaticum and / or Caryophyllus aromaticus L.) against Gramnegative bacterial strains Salmonella sp, Klebsiella pneumoniae Carbapenemase, Pseudomonas aeruginosa, against Gram-positive bacteria Streptococcus mutans, Streptococcus pyogenes, Streptococcus agalactiae, Staphylococcus aureus and fungi Candida albicans. The antimicrobial evaluation of the extracts was performed by the disc-diffusion method and indicated that all the strains used in this study are sensitive to the extracts tested. With the increase in the incidence of infectious diseases caused by bacterial resistance due to 
the irrational use of antimicrobials, the emergence of multiresistant strains, mainly related to hospitalized and immunocompromised patients, became of great scientific interest in the last decades the search and obtainment of substances that present antimicrobial activity and which inhibit the growth of pathogenic microorganisms.

Keywords: Antimicrobial activity, Syzygium aromaticum and /or Caryophyllus aromaticus L., Hospital disinfection, Clove.

\section{INTRODUÇÃO}

As plantas são dotadas de mecanismos químicos para se defender de herbívoros e patógenos, tal fato, explica a complexa constituição química das plantas, as substâncias produzidas por elas e seus metabólitos utilizados para atacar seus predadores podem também ter efeito sobre males que afligem o homem.

Alguns metabólitos secundários de plantas que são produzidas pelo seu próprio metabolismo podem também alcançar alvos terapêuticos em doenças humanas (FERREIRA, 2010).

O uso de plantas para tratamento de enfermidades é uma prática tão antiga quanto a civilização humana, sendo possível encontrar registros que descrevem as terapias em continente Africano (Egito) e Asiático (China), com suas propriedades medicinais de diversas plantas (ALMEIDA, 1993).

Portanto, o uso de plantas como tratamento terapêutico é algo muito antigo e vem sendo passado como tradição de geração para geração. No entanto, apesar das plantas medicinais já estarem arraigadas na cultura popular, nas últimas décadas, o interesse pela fitoterapia, nome dado ao tratamento de doenças mediante o uso de plantas, teve um aumento considerável entre usuários, pesquisadores e serviços de saúde. A Organização mundial da saúde (OMS, 1991) já reconhece o potencial das plantas medicinais no âmbito sanitário e na atenção básica à saúde, uma vez que toda planta que possui sua eficácia terapêutica e princípios ativos comprovados cientificamente pode ser utilizada pela população como forma de suprir as suas necessidades básicas de saúde. Por sua vez, o Ministério da Saúde recomenda e indica diversas plantas medicinais aprovadas pela ANVISA, uma vez que seu uso está consagrado na cultura da medicina popular brasileira (FERREIRA, 2010).

As plantas consideradas medicinais beneficiaram, e continuam beneficiando a humanidade. Não necessitam dos testes clínicos como os fármacos sintéticos, credenciaram-se pelo seu uso tradicional ao longo de séculos. Ainda nos dias de hoje muitas são utilizadas para tratamento, mesmo havendo medicamentos sintéticos no mercado para o tratamento das mesmas patologias (FERREIRA, 2010).

Sendo assim, o uso tradicional das plantas como medicamentos, contribuíram para a intensa investigação no qual óleos essenciais e extratos poderiam ser úteis em condições terapêuticas específicas (SIMÕES et al., 2007).

Dentre inúmeras plantas estudadas destacam-se Syzygium aromaticum e/ou Caryophyllus aromaticus L., popularmente conhecido como cravo-da-índia, o qual é o foco dessa pesquisa que visa investigar suas propriedades antimicrobianas do extrato alcoólico de Syzygium aromaticum e/ou Caryophyllus aromaticus $L$.

O craveiro-da-índia, de nome científico (Syzygium aromaticum e/ou Caryophyllus aromaticus L.), pertence à família Myrtaceae e originária da Indonésia, conta com cerca de 3.000 espécies de árvores e arbustos tropicais e subtropicais. A copa do craveiro bem verde 
geralmente de formato piramidal, folhas e seus botões florais secos de importância farmacológica pode ser observada em (Figura 1).

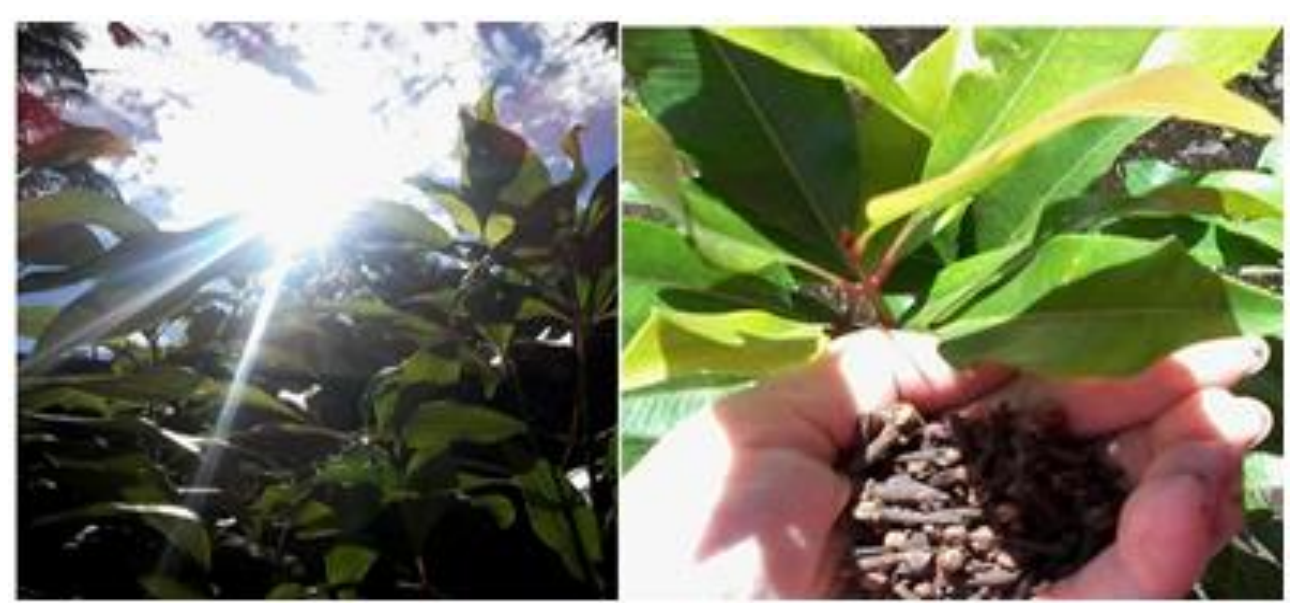

Figura 1- Cravo-da-índia. Partes fisiológicas que compõe Syzygium aromaticum e/ou Caryophyllus aromaticus L. (Fonte: Próprio autor).

Seu nome científico varia com a classificação adotada; mais recentemente, foi classificado como Syzygium aromaticum (L.) Merr. et Perry, existindo, porém, várias citações anteriores, a saber: Eugenia caryophyllus (Sprengel) Büllock et Harrison, Caryophyllus aromaticus L, Eugenia caryophyllata Tumb e Eugenia aromatica (L) Baill (MAEDA et al, 1990).

Segundo Mazzafera (2003) as folhas são semelhantes às do louro, ovais, opostas e de coloração verde brilhante, com numerosas glândulas de óleo visíveis contra a luz (Figura 2).

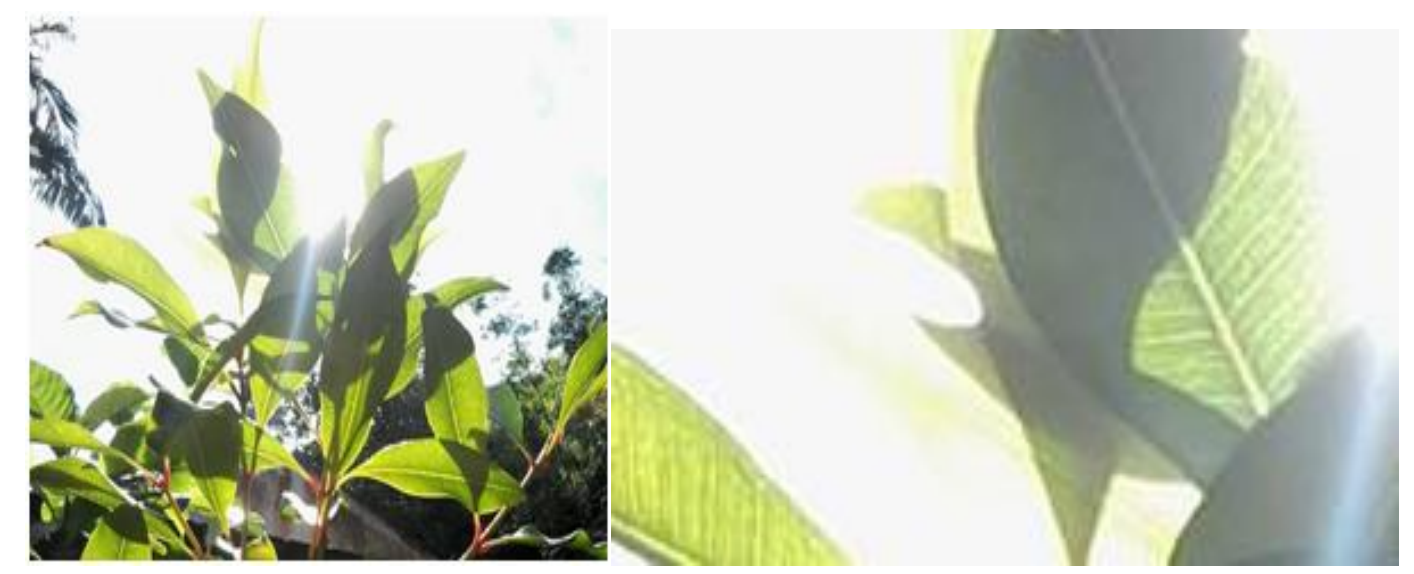

Figura 2- Glândulas de óleo visíveis contra a luz de cravo-da-índia (Syzygium aromaticum e/ou Caryophyllus aromaticus L.) (Fonte: Próprio autor).

A parte da planta que tem importância comercial e farmacológica são os botões florais, desses botões pode ser extraído o óleo essencial, cuja substância majoritária é o eugenol (MAZZAFERA, 2003). A substância que deixa o cravo com um sabor e aroma marcante é o eugenol, um composto fenólico volátil. Nas folhas, segundo Raina e colaboradores et al. (2001) apud Mazzafera (2003), o eugenol representa cerca de 95\% de óleo extraído. 
O cravo-da-índia ainda possui outras substâncias como o acetato de eugenol e $\beta$ cariofileno (MAZZAFERA, 2003).

Dentre os diferentes grupos de patógenos causadores de infecção hospitalar estão fungos, vírus e bactérias. No entanto, o grupo que mais se destaca é o das bactérias que constituem a flora humana e que normalmente não trazem riscos a indivíduos saudáveis, embora possam causar infecções em indivíduos com estado clínico comprometido (ANVISA, 2004). Microrganismos podem causar doenças e podem ser transmitidos pelas mãos (Figura 3A) ou vetores mecânicos, como as formigas (Figura 3B).

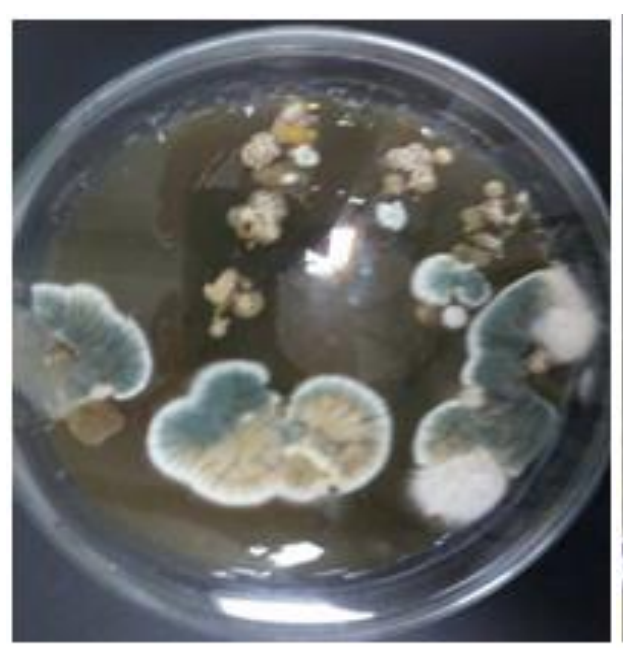

A

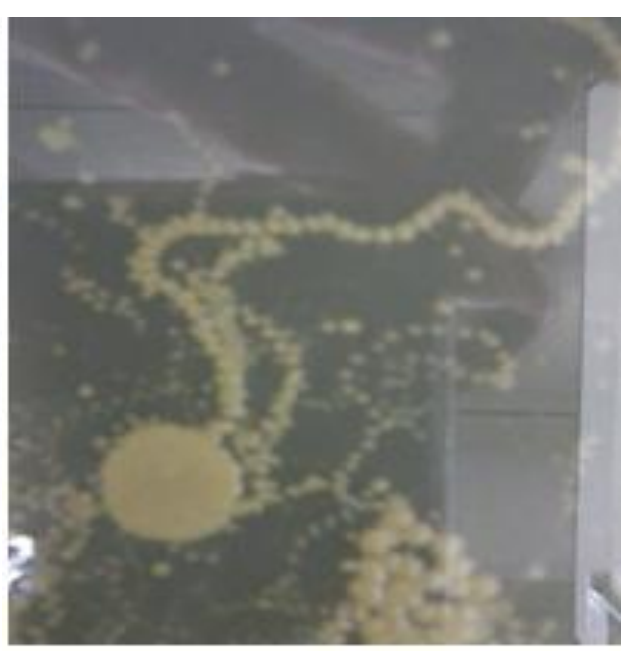

B

Figura 3 - Propagação de microrganismos. A) Observação macroscópica de microrganismos em placa, após contato das mãos em superfícies; B) Observação do curso de vetores (formigas) (Fonte: Próprio autor).

A redução na eficácia terapêutica a diversos antimicrobianos é preocupante, a procura de substâncias que apresentem atividade antimicrobiana é grande. O objetivo deste trabalho foi a obtenção de extrato bruto, avaliar a atividade antimicrobiana frente às linhagens bacterianas Gram-negativas como Salmonella sp, Klebsiella pneumoniae Carbapenemase e Pseudomonas aeruginosa; frente às bactérias Gram-positivas: Streptococcus mutans, Streptococcus pyogenes, Streptococcus agalactiae e Staphylococcus aureus e o fungo Candida albicans.

Mesmo com a ação diversificada dos antimicrobianos, a exposição excessiva aos fármacos por longos períodos contribuiu para o desenvolvimento de diversos mecanismos de resistências bacterianas (WRIGHT, 2005).

A resistência apresentada por microorganismos traz uma redução na eficácia terapêutica dos medicamentos normalmente indicados para tratamento e controle de diversas infecções, o que torna o assunto preocupante, diante deste fato, medidas defensivas a serem tomadas incluem o controle do uso de antimicrobianos, pesquisas que ajudem a compreender os mecanismos de resistência microbiana (NASCIMENTO et al., 2000), e a procura por novas drogas com ação antimicrobiana

Este trabalho teve como objetivo testar novas substâncias que apresentem atividade antimicrobiana contra patógenos humanos e que podem estar envolvidos em casos de infecção hospitalar, a fim de agregar novos princípios químicos ao combate a resistência microbiana. 


\section{METODOLOGIA}

\section{Obtenção de Material Vegetal}

Foram utilizados botões florais secos de cravo-da-índia (Syzygium aromaticum e/ou Caryophyllus aromaticus L.). Os botões florais de Syzygium aromaticum e/ou Caryophyllus aromaticus $L$., foram obtidos em sua forma industrializada (Kitano $\left.{ }^{\circledR}\right)$, os quais já vêm secos.

\section{Preparação do extrato}

Foram feitos três extratos alcoólicos a partir do cravo (Syzygium aromaticum e/ou Caryophyllus aromaticus L.) O primeiro com mais tempo de repouso em etanol do que o segundo, e o terceiro extrato foi obtido através do primeiro extrato com o objetivo de verificar a viabilidade do extrato após algum tempo de armazenamento. Os extratos foram feitos para verificar se o princípio ativo dos compostos foi obtido em ambas as formas de extração.

\section{Extrato $n^{o} 1$}

Cerca de 20 botões florais de cravo foram colocados em Becker contendo $20 \mathrm{ml}$ de etanol $70 \%$. A solução ficou vedada com papel filme e em repouso à temperatura ambiente durante 02 (dois) meses.

Após os 02 (dois) meses (Figura 4A), o papel filme que vedava a solução foi perfurado e deixado por 10 (dez) dias em repouso em temperatura ambiente, a fim de promover a evaporação do etanol, ao final restando $10 \%$ do meio líquido, até restar uma massa pastosa com formação de grânulos cristalizados no fundo do recipiente (Figura 4B). A solução foi levada à geladeira para ser ressuspendida em $180 \mu \mathrm{l}$ de água destilada para o teste das cepas.

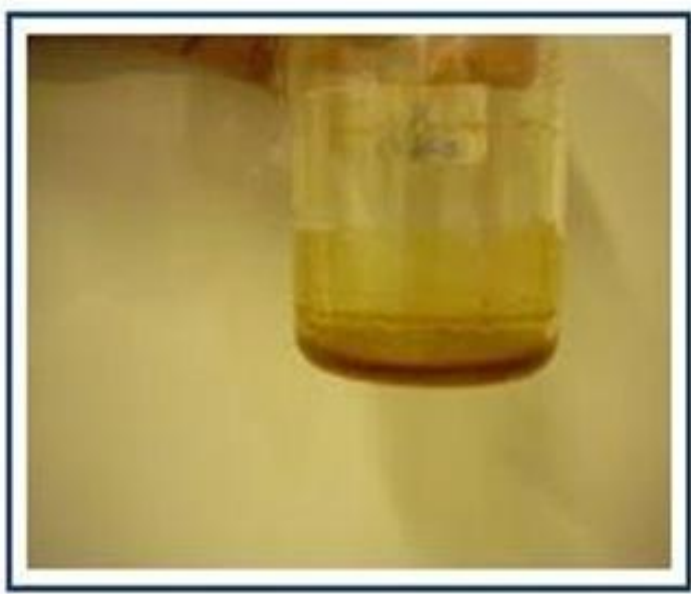

A

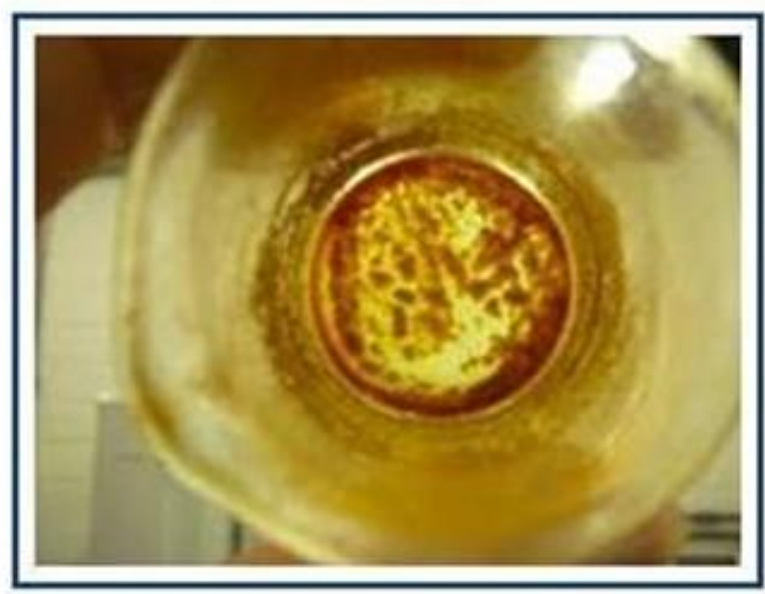

B

Figura 4 - Preparo do extrato de Syzygium aromaticum e/ou Caryophyllus aromaticus L. A) Extrato concentrado de cravo-da-índia, após a evaporação do etanol. B) Massa pastosa com formação de grânulos cristalizados (Fonte: Próprio autor). 


\section{Extrato $n^{\circ} 2$}

Foram colocados em um Becker $2 \mathrm{~g}$ de cravo em $20 \mathrm{ml}$ de etanol à $70 \%$, deixado em repouso por 17 dias. Após o repouso a solução foi filtrada e depois deixada coberta com filme plástico contendo furos para a evaporação do etanol. Com finalidade de acelerar o processo de evaporação a solução foi colocada no rota-evaporador por um período de $20 \mathrm{~min}$, à $80^{\circ} \mathrm{C}$, ao final restando $10 \%$ da solução. Após o repouso, a solução que apresentou um aspecto mais oleoso, foi mantida em geladeira.

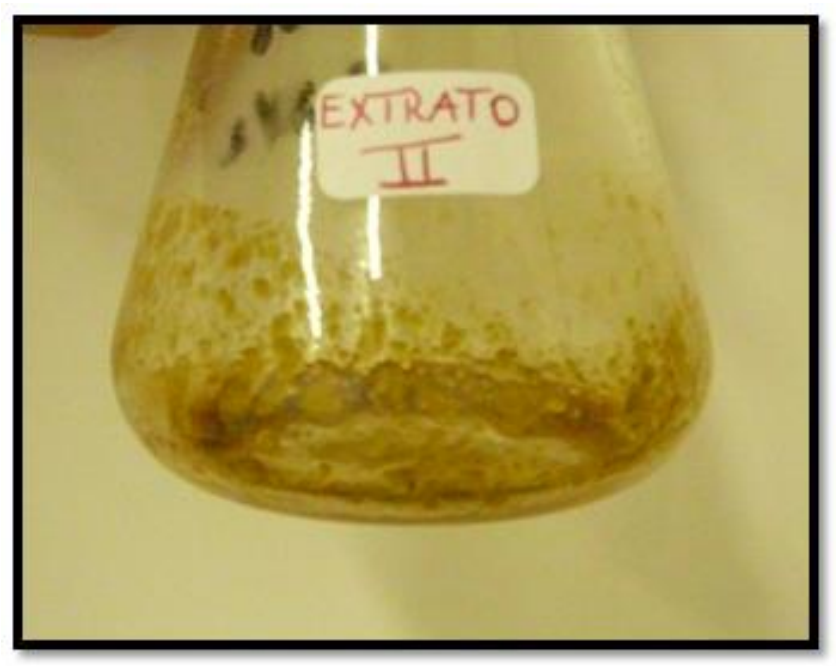

Figura 5 - Preparo do extrato de cravo-da-índia (Syzygium aromaticum e/ou Caryophyllus aromaticus L.). Solução de consistência oleosa, após o processo de evaporação por rotaevaporador (Fonte: Próprio autor).

\section{Extrato $n^{\circ} 3$}

Parte da solução do extrato $\mathrm{n}^{\circ} 01$, contendo cravo e etanol à $70 \%$, foi armazenada por cerca de 09 (nove) meses em frasco âmbar. Posto para evaporar em temperatura ambiente, restando $10 \mathrm{ml}$ da solução após 07 (sete) dias.

O extrato $n^{\circ} 01$ após evaporação do etanol (Figura 6) em visualização de microscópio óptico possui aspecto de grânulos cristalizados.

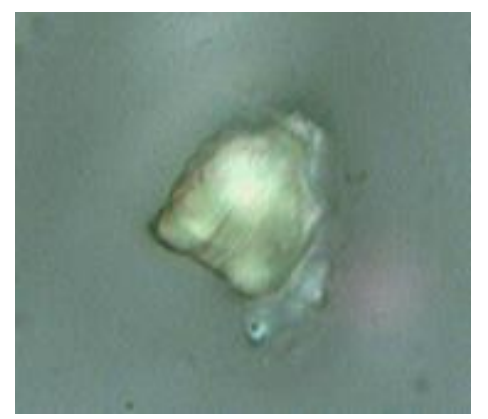

Figura 6 - Extrato de cravo-da-índia (Syzygium aromaticum e/ou Caryophyllus aromaticus L.). Visualização microscópica do extrato de cravo-da-índia (Syzygium aromaticum e/ou Caryophyllus aromaticus L.) (Fonte: Próprio autor). 


\section{Obtenção e manutenção de microrganismos}

Foram avaliadas qualitativamente a ação antimicrobiana in vitro do extrato de botões florais secos de cravo-da-índia (Syzygium aromaticum e/ou Caryophyllus aromaticus L.) frente às bactérias Gram-negativas Salmonella sp, Klebsiella pneumoniae Carbapenemase e Pseudomonas aeruginosa., frente às bactérias Gram-positivas Streptococcus mutans, Streptococcus pyogenes, Streptococcus agalactiae e Staphylococcus aureus e o fungo Candida albicans.

As linhagens bacterianas Gram-positivas Streptococcus mutans, Streptococcus pyogenes e Staphylococcus aureus e Gram-negativa Salmonella sp, e a linhagem fúngica Candida albicans, utilizadas neste trabalho foram gentilmente cedidas pelo Laboratório de Pesquisa em Microbiologia Aplicada da Universidade São Francisco (USF), campus de Bragança Paulista.

As cepas foram repicadas 24 horas antes do preparo do inóculo, sendo $S$. aureus e Salmonella sp. repicadas em ágar nutriente (Himedia) incubadas em estufa à $37^{\circ} \mathrm{C}$ por 24 horas e $S$. pyogenes e $S$. mutans repicadas em ágar sangue (Himedia) e incubadas por 24 horas em jarra de microaerofilia, o fungo Candida albicans em ágar Sabouraud.

Dentro das Bactérias Beta- hemolíticas foi dado ênfase a duas espécies patogênicas principais:

- S. pyogenes

- S. agalactiae

A identificação de Streptococcus pyogenes foi confirmada pela coloração de Gram e provas bioquímicas, onde observou-se a presença de estreptococo Gram positivo, catalase negativa, Beta hemolítico, sensível a Bacitracina (Figura 7).

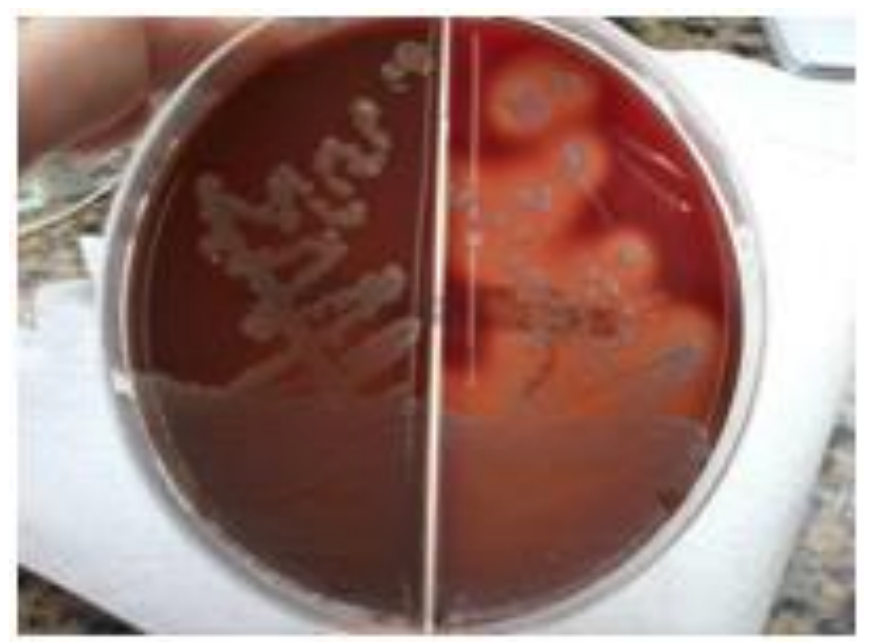

Figura 7 - amostra de estreptococo beta hemolítico com hemólise total (transparente e translúcido) em ágar sangue (Fonte: Próprio autor).

Para separar os Beta hemolíticos foi necessário teste de sensibilidade ao antibiótico Bacitracina;

- Sensíveis a Bacitracina - S. pyogenes

- Resistente a Bacitracina - S. agalactiae

As bactérias Klebsiella Pneumoniae Carbapenemase, Pseudomonas aeruginosa. e Streptococcus agalactiae, foram obtidos de amostra clínica. Klebsiella Pneumoniae 
Carbapenemase (KPC) é um bacilo Gram-negativo, produz enzimas betalactamases com resistência a cefalosporinas e carbapenemases, que oferece resistência a antibióticos carbapenêmicos. O crescimento e o isolamento de colônias brilhantes e mucóides da KPC em placa de ágar MacConkey (Figura 8B) e a identificação da espécie através de testes bioquímicos (Figura 8A).

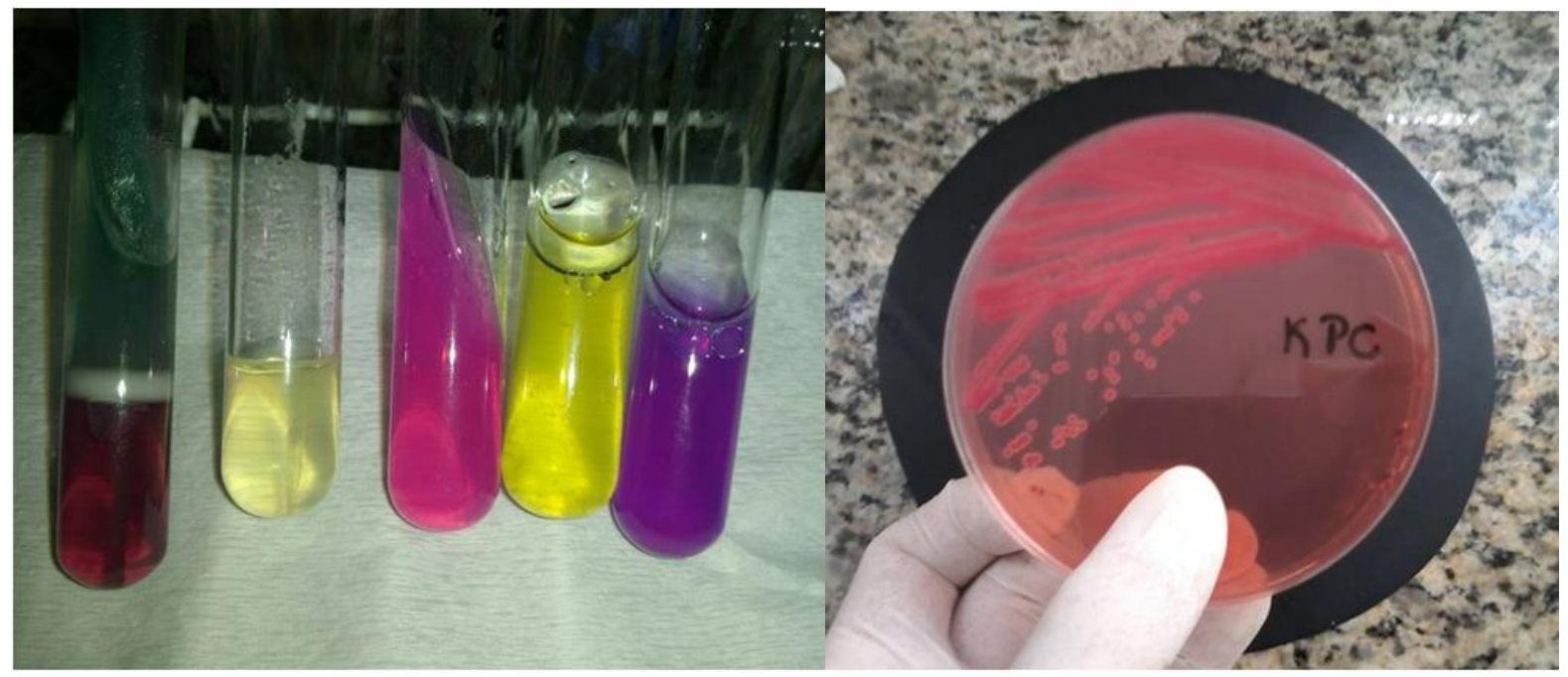

A

B

Figura 8 - Isolamento e identificação da Bactéria Gram-negativa Klebsiella Pneumoniae Carbapenemase A) testes bioquímicos: Oxidase (-), MCS (+), Citrato (+, maioria), Indol (-), Motilidade (-, sempre), Ureia (-) para ozaenae e Ureia (+) pneumoniae, Arginina (-), Lisina $(+)$, VP (+). B) Desenvolvimento de colônias rosadas e brilhantes de aspecto gomoso (mucóide) de KPC (Fonte: Próprio autor).

\section{Avaliação da Atividade Antimicrobiana}

\section{Preparo do inóculo}

Para a preparação do inóculo foram repicadas bactérias através da técnica de esgotamento e deixadas em crescimento por $24 \mathrm{~h}$ em temperatura de $36^{\circ} \mathrm{C}$ e tubos contendo salina que foram auto-clavados.

\section{Difusão em Disco}

Os testes de sensibilidade para avaliar a atividade antimicrobiana dos extratos alcoólicos dos botões florais secos de Syzygium aromaticum e/ou Caryophyllus aromaticus L., foram realizados através do teste qualitativo de difusão em disco da seguinte forma:

Após o crescimento bacteriano de 24 horas, observou-se colônias isoladas das quais selecionou-se de 3 a 4 colônias que foram aplicadas em solução salina estéril a $0,85 \% \mathrm{NaCl}$ até atingir a turbidez correspondente ao tubo 0,5 da escala de MacFarland $(0,05 \mathrm{~mL}$ de cloreto de bário dihidratado a $1,175 \%$ em $9,95 \mathrm{ml}$ de ácido sulfúrico 1\%) correspondendo aproximadamente $1,5 \times 10^{8} \mathrm{UFC} / \mathrm{ml}$.

Os meios de cultura ágar Mueller Hinton foram retirados da refrigeração e deixados em temperatura ambiente. 
Introduziu-se o swab no tubo de ensaio contendo a suspensão bacteriana e apertou-se firmemente contra a parede interna do tubo, acima do nível do líquido, a fim de retirar qualquer excesso de inóculo do swab.

A superfície seca da placa de Ágar Mueller- Hinton sólido foi semeada esfregando o swab em toda a superfície estéril do Ágar, girando a placa aproximadamente $60^{\circ}$ cada vez, a fim de assegurar a distribuição uniforme do inóculo e com passo final passara-se o swab na margem da placa de Ágar.

Esterilizou-se a pinça e fixou-se os discos de papel-filtro (Cecon) de $12 \mathrm{~mm}$ estéreis no meio de cultura colocados na superfície da placa de Ágar semeada, frente às bactérias Salmonella sp., Streptococcus mutans, Streptococcus pyogenes, Staphylococcus aureus e Candida albicans; Para Klebsiella pneumoniae Carbapenemase, Pseudomonas aeruginosa e Streptococcus agalactiae, foram utilizados discos de menor diâmetro (6 mm).

Cada disco foi pressionado de encontro à placa, de maneira a assegurar contato com a superfície de Ágar e em seguida os discos foram impregnados com $60 \mu \mathrm{l}$ de cada extrato preparado previamente. As placas foram incubadas por um período de $24 \mathrm{~h}$, a $37^{\circ} \mathrm{C}$ e após este período procedeu-se a realização da leitura dos resultados.

Todos os testes foram realizados em duplicata sendo considerada a média aritmética das duas medidas, considerado como atividade de inibição a presença de halos de inibição indicando as cepas sensíveis aos extratos testados neste estudo.

\section{RESULTADOS E DISCUSSÃO}

Os resultados obtidos através do método de disco-difusão puderam indicar que houve a formação do halo de inibição de crescimento em todas as cepas utilizadas neste estudo (Tabela 1).

Tabela 1. Resultados dos testes de difusão em disco, média da duplicata dos halos de inibição do crescimento bacteriano em $\mathrm{mm}$ (milímetro).

\begin{tabular}{llll}
\hline \multicolumn{1}{c}{ Microrganismos } & $\begin{array}{l}\text { Extrato } \mathrm{n}^{\mathbf{0}} \mathbf{1} \\
(\mathrm{mm})\end{array}$ & $\begin{array}{l}\text { Extrato } \mathrm{n}^{\mathbf{0}} 2 \\
(\mathrm{~mm})\end{array}$ & $\begin{array}{l}\text { Extrato }^{\mathbf{0}} \mathbf{3} \\
(\mathrm{mm})\end{array}$ \\
\hline $\begin{array}{l}\text { Salmonella sp } \\
\text { Streptococcus mutans }\end{array}$ & 20 & 17 & 18 \\
$\begin{array}{l}\text { Streptococcus } \\
\text { pyogenes }\end{array}$ & 39 & 18 & 20 \\
Staphylococcus aureus & 30 & 38 & 34 \\
Candida albicans & 25 & 24 & 24 \\
\hline
\end{tabular}

Fonte: Próprio autor

Candida albicans é um fungo leveduriforme que pode causar candidíase, podendo ser desde uma micose superficial até uma infecção sistêmica, passando para a circulação sanguínea, por esse motivo torna-se importante a abordagem clínica em pacientes imunocomprometidos, principalmente portadores de Vírus da imunodeficiência Humana (HIV). O halo de inibição do crescimento de Candida albicans pode ser observado (Figura 9).

Foram realizados testes com antifúngicos quimioterápicos como Nistatina, Voriconazol e Fluconazol (Figura 9A) e com o extrato n $^{\circ} 02$ e 03 de cravo-da-índia (Figura 9B). 


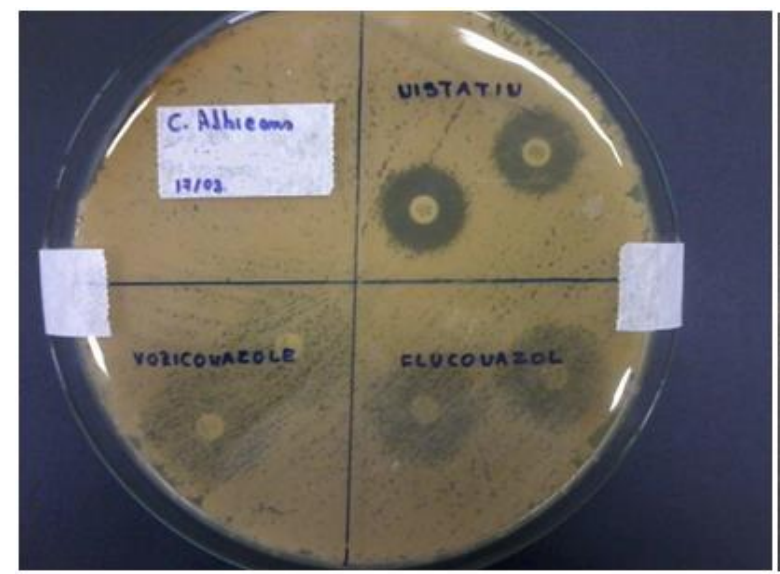

A

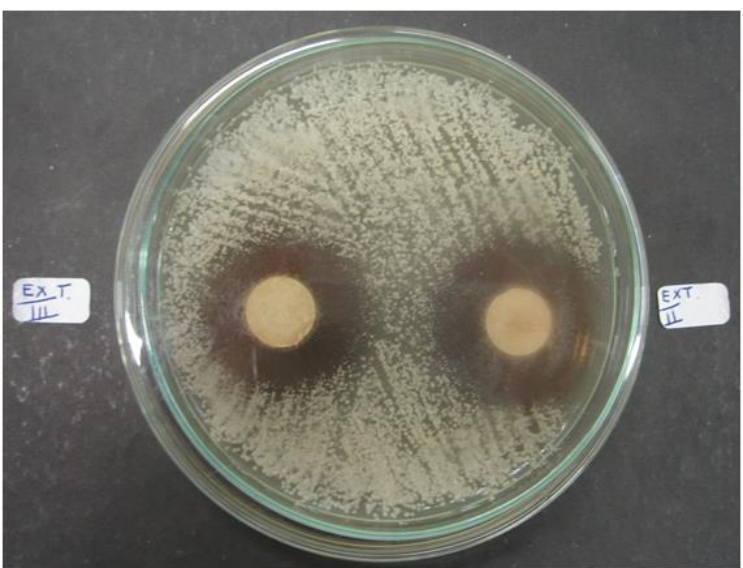

B

Figura 9 - Candida albicans. A) halo de inibição de medicamento antifúngico (Nistatina, Voriconazol, Fluconazol) B) halo de inibição do extrato de cravo-da-índia (Syzygium aromaticum e/ou Caryophyllus aromaticus L.) (Fonte: Próprio autor).

O gênero Staphylococcus pertence à família Micrococcae e compreende várias espécies dentre elas o Staphylococcus aureus (Figura 10), bactéria Gram-positiva envolvida em vários casos de infecção em humanos. Houve a formação do halo de inibição do crescimento, frente ao extrato $\mathrm{n}^{\mathrm{o}} 01$ de cravo-da-índia (Figura 10).

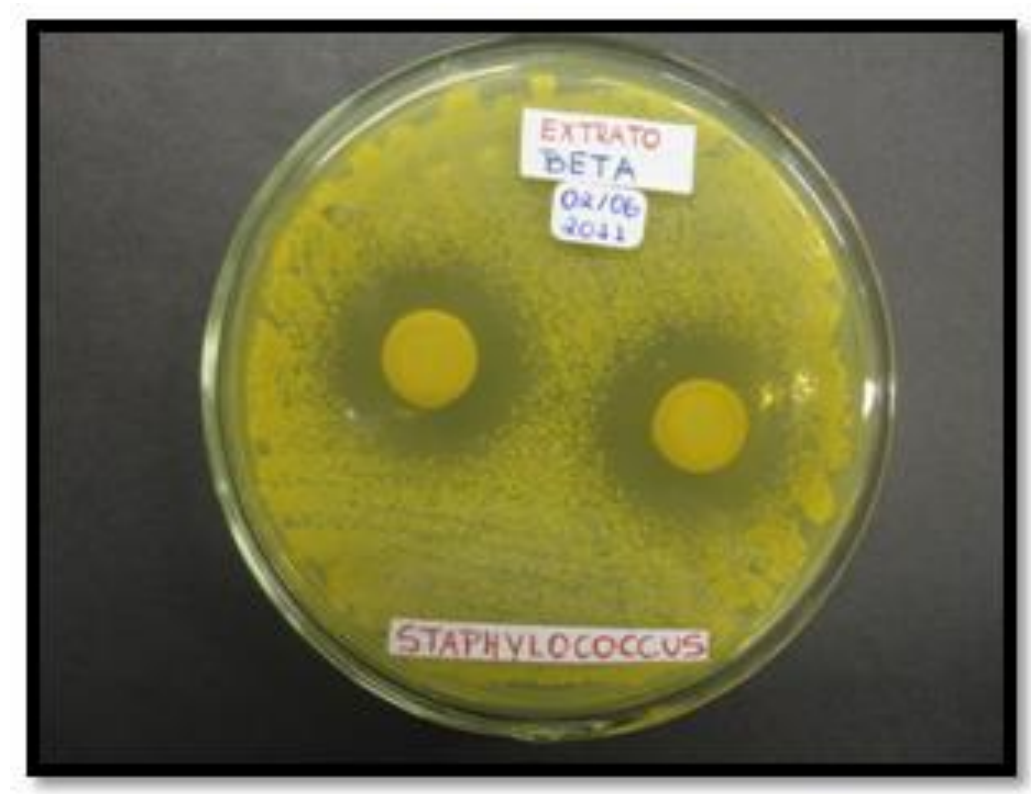

Figura 10 - Teste em difusão em disco com Staphylococcus aureus. Halos formados com o extrato $\mathrm{n}^{\circ} 01$ de cravo-da-índia (Fonte: Próprio autor).

A Bactéria Pseudomonas aeruginosa é um bacilo Gram-negativo com colônias de coloração transparente ou esverdeada, Pseudomonas aeruginosa ATCC 27853 (Figura 11 A), com odor de cheiro adocicado característico de uva, podem apresentar aspecto semelhante a bactéria Proteus (colônia transparente), portanto sua diferenciação está relacionada com a oxidase, Pseudomonas são oxidase positiva. 


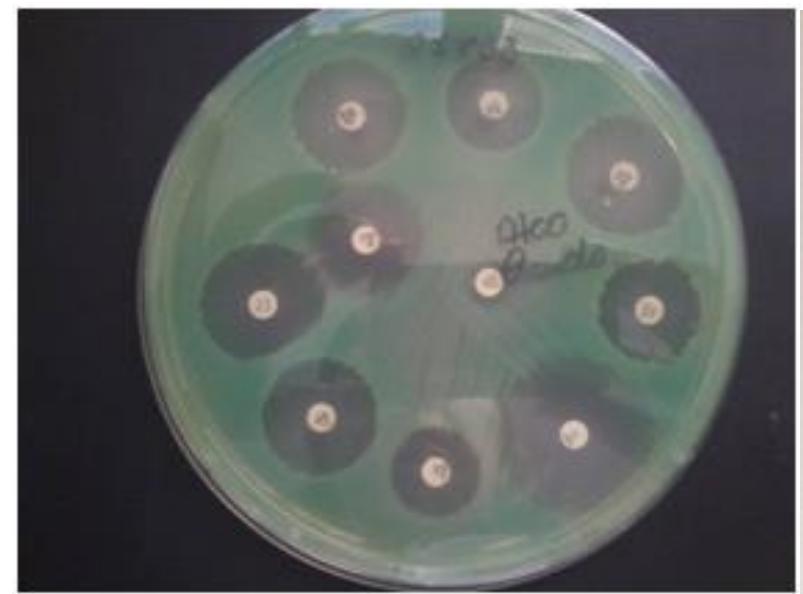

A

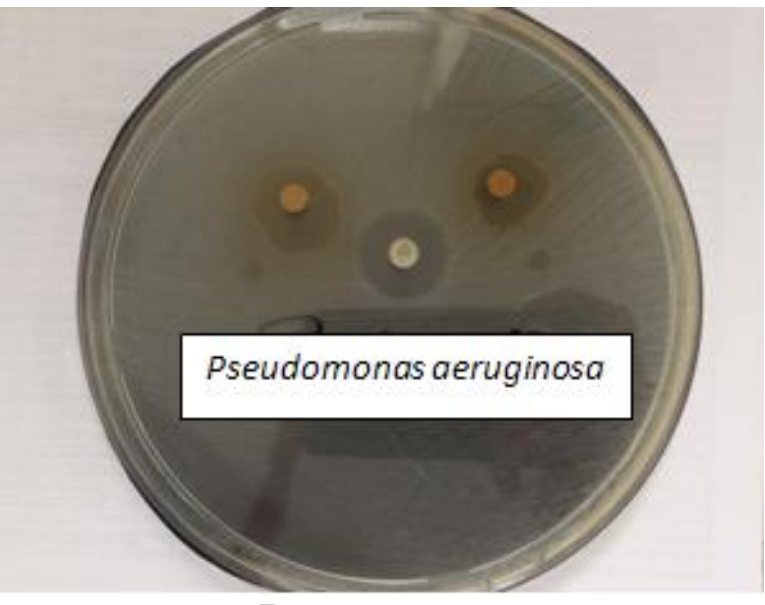

B

Figura 11- Pseudomonas aeruginosa. A) observação dos halos formados em antibiograma para Pseudomonas aeruginosa B) observação de halos formados a partir do extrato $\mathrm{n}^{\circ} 01$ de cravo-da-índia (Fonte: Próprio autor).

Gênero Klebsiella pneumoniae Carbapenemase (KPC) bactéria gram-negativa, não apresenta odor característico, encapsulado, anaeróbia facultativa da família das Enterobacterias (Figura12).

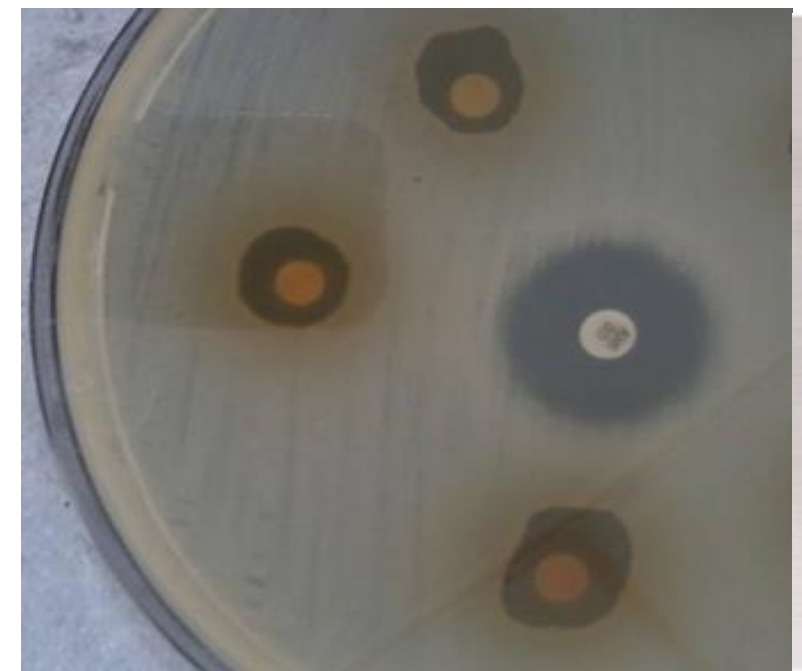

A

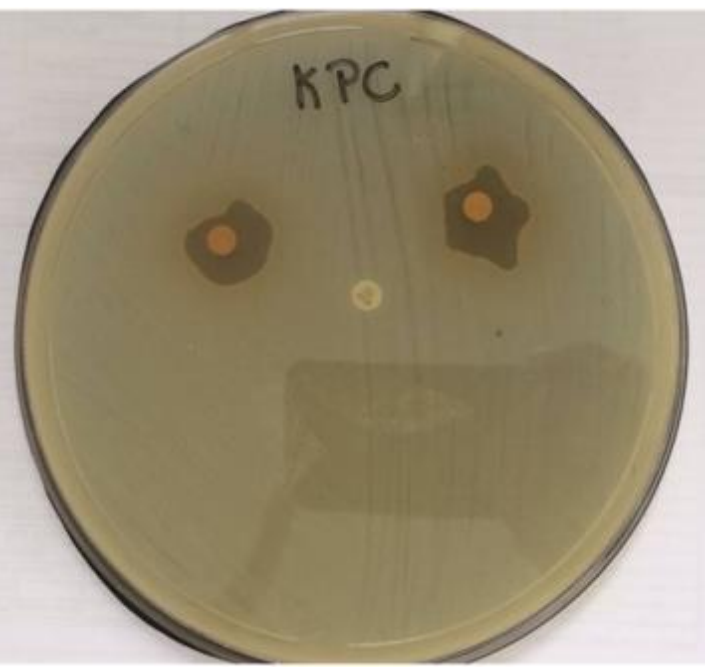

B

Figura 12- Bactéria Klebsiella pneumoniae Carbapenemase, obtidas de amostras clínicas; A) halo de inibição irregular KPC, devido ao uso de disco de diâmetro menor; B) visualização da comparação do disco AMP (ampicilina) e da formação do Halo do extrato $\mathrm{n}^{\circ} 01$ de Syzygium aromaticum e/ou Caryophyllus aromaticus L. (Fonte: Próprio autor).

A formação de halos de inibição do crescimento irregular ocorreu também com as duas outras bactérias Pseudomonas aeruginosa e Streptococcus agalactiae, portanto, não foi possível a medição exata dos halos. 


\section{CONCLUSÃO}

Através dos resultados obtidos, verifica-se que o extrato $n^{\circ} 01$ tem maior efeito que os demais, o que pode indicar que um maior tempo de extração em etanol possa adquirir maior concentração de princípios ativos. A resistência microbiana é um dos principais motivos que leva à busca de novos compostos que inibam o crescimento de microrganismos patógenos.

Em relação aos microrganismos cedidos pelo Laboratório de Pesquisa em Microbiologia da Universidade São Francisco (USF), campus de Bragança Paulista, há uma maior sensibilidade do Streptococcus pyogenes ao composto. Em ordem de maior sensibilidade, os resultados se mostram da seguinte forma: Streptococcus pyogenes; Staphylococcus aureus; Candida albicans; Streptococcus mutans; Salmonella sp. Quanto aos microrganismos obtidos de amostra clínica, Klebsiella pneumoniae Carbapenemase, Pseudomonas aeruginosa. e Streptococcus agalactiae observou-se a sensibilidade, mas esta não pôde ser medida devido a irregularidade dos halos.

Ainda pode-se concluir, através dos resultados, que a propriedade antimicrobiana pouco se perdeu do extrato $\mathrm{n}^{\circ} .01$ para o extrato $\mathrm{n}^{\circ} .03$.

A finalidade deste trabalho foi demonstrar a importância das propriedades antimicrobiana a partir de produtos naturais que tem sido comprovada em pesquisas de todo o mundo, utilizando técnicas de ensaio in vitro em testes de susceptibilidade, verificando assim a importância dos estudos aprofundados neste tema. A procura de novos princípios ativos com ação antimicrobiana tanto de origem sintética como de origem vegetal tem sido investigada em larga escala com objetivo de controlar a disseminação de patógenos.

Portanto, apesar de uma discreta diferença entre os extratos, o que pôde-se verificar é que os extratos preparados alcançaram o objetivo, ou seja, apresentaram atividade antimicrobiana. Os resultados desta pesquisa visam estimular o prosseguimento das pesquisas.

\section{REFERÊNCIAS}

AGÊNCIA NACIONAL DE VIGILÂNCIA SANITÁRIA. Manual de Microbiologia Clínica para Controle de Infecção em Serviços de Saúde. 1. ed.; Editora Agência Nacional de Vigilância Sanitária; 2004. Disponível em: <http://bvsms.saude.gov.br/bvs/publicacoes/manual_microbiologia_completo.pdf $>$. Acessado em: 10/03/2018.

ALMEIDA, E. R. Plantas medicinais brasileiras.1 ED. São Paulo: Hemus, 1993.

BARRY, A. L; THORNSBERRY, C., Et al. Susceptibility test: diffusion Test procedures. Manual of clinical microbiology. 5.ed. Washington, DC: American Society for Microbiology, p. $1117-1125 ; 1991$.

FERREIRA, V. F.; PINTO, A. C. A fitoterapia no mundo atual. Quím. Nova, v.33, n.9, p. 1829-1829, 2010.

FERREIRA, V. F. A fitoterapia no mundo atual. Quím. Nova, vol.33, no.9; São Paulo, 2010. Disponível em: <http://www.scielo.br/scielo.php?script=sci_arttext\&pid=S010040422010000900001>. Acessado em: 22/04/2018. 
GRIMOUD, A.M.; Et al. Colonization of the oral cavity by Candida species: risk factors in long-term geriatric care. J Oral Sci; v.45, $\mathrm{n}^{\circ} .1$; p. 51-55; 2003. Disponível em: <https://pdfs.semanticscholar.org/0bd7/0402c5551ed71df95dc23dbd6c4e22aca8e7.pdf>.

Acessado em: 10/03/2018.

MAEDA, J. A.; Et al. Craveiro-da-índia: Características físicas das sementes e seus efeitos na germinação e desenvolvimento vegetativo. Campinas; $v^{\circ} .49, n^{\circ} .1$, p. 23-36; 1990. Disponível em: <http://www.scielo.br/pdf/brag/v49n1/03.pdf>. Acessado em: 22/04/2018.

MAZZAFERA, P. Efeito alelopático do extrato alcoólico do cravo-da-índia e eugenol. Revista Brasil. Bot., V.26, n.2, p.231-238, jun/2003. Disponível em: $<$ http://www.scielo.br/scielo.php?pid=S0100-

84042003000200011\&script=sci_abstract\&tlng=pt>. Acessado em: 14/04/2018.

NASCIMENTO, G. F. Et al. Antibacterial activity of plant extracts and phytochemicals on antibiotic resistant bacteria. Brazilian Journal of Microbiology; v.31, n.4, p.247-56; 2000. Disponível em: <http://www.scielo.br/scielo.php?script=sci_arttext\&pid=S151783822000000400003>. Acessado em: 15/04/2018.

ORGANIZACIÓN Mundial de laSalud (OMS). Medicina tradicional y asistencia sanitaria moderna. Conselho Executivo; Foro mundial de lasalud. Revista Internacional de Desarrollo Sanitario; v.12, n.1, p.120; 1991. Disponível em: <http://apps.who.int/medicinedocs/documents/s21201es/s21201es.pdf >. Acessado em: 22/04/2018.

SIMÕES, C.; Et al. Farmacognosia da planta ao medicamento. Editora Universidade/ URFGS, $6^{\circ}$ ed. Porto Alegre/Florianópolis; UFSC, 2007.

SOUZA, M. M.; Et al. Método de avaliação biológica de produtos naturais e sintéticos. Itajaí: Ed. Univali, 2003.

TAVARES, W. Bactérias Gram-positivas problemas: resistência do estafilococo, do enterococo e do pneumococo aos antimicrobianos. Rev. Soc. Brasil. Med.; v. 33, p. 281301; 2000. Disponível em: <http://www.scielo.br/scielo.php?pid=S0037$86822000000300008 \&$ script=sci_abstract\&tlng=pt $>$. Acessado em: 10/03/2018.

WRIGHT, G. D. Bacterial resistance to antibiotics. Enzymatic degradation and modification. Advanced Drug Delivery Reviews; v.57, p. 1451-1470; 2005. Disponível em: <https://www.sciencedirect.com/science/article/pii/S0169409X05000980?via\%3Dihub>.

Acessado em: 15/04/2018.

Publicado em 17/12/2019 